\title{
IMPLANTE TUMORAL EM SÍTIO DE TROCARTE APÓS COLECISTECTOMIA LAPAROSCÓPICA
}

\author{
TROCAR-SITE METASTASIS FOLLOWING LAPAROSCOPIC \\ CHOLECYSTECTOMY
}

\author{
Júlio Cezar Uili Coelho, TCBC-PR ${ }^{1}$ \\ Marcelus V. A. S. Nigro ${ }^{2}$ \\ Cleverson Winston de Liz Medeiros ${ }^{2}$
}

\section{INTRODUÇÃO}

Neoplasia da vesícula biliar incidental em pacientes submetidos à colecistectomia laparoscópica tem sido descrita freqüentemente. ${ }^{1}$ Esta ocorrência desperta discussões quanto à possibilidade de implantação tumoral em sítio de trocartes e de favorecer uma disseminação peritonial mais precoce. Os autores relatam dois casos de implante tumoral no local de inserção do trocarte após colecistectomia laparoscópica realizada em pacientes com carcinoma de vesícula biliar.

\section{RELATO DOS CASOS}

\section{Caso 1}

Uma paciente de 68 anos foi submetida à colecistectomia laparoscópica por colecistite crônica, não apresentando história de icterícia, emagrecimento e alterações de provas de função hepática. A vesícula durante o procedimento não apresentava sinais de espessamento, aderências ou acometimento hepático. A dissecção e a retirada da vesícula transcorreram sem intercorrências, não havendo perfuração da mesma ou extravasamento de bile. A vesícula biliar foi retirada pela incisão do trocarte umbilical, sem o uso de saco plástico. A paciente obteve alta no primeiro dia de pós-operatório.

O exame histológico revelou a presença de adenocarcinoma comprometendo mucosa e muscular, não suspeitado anteriormente. A paciente recusou-se a ser submetida à uma operação radical adicional e à terapia adjuvante.
Sete meses após a alta hospitalar apresentou dor abdominal em epigástrio e massa no sítio do trocarte umbilical. A paciente foi submetida à ressecção do implante, confirmado posteriormente no exame patológico como adenocarcinoma (Figura 1).

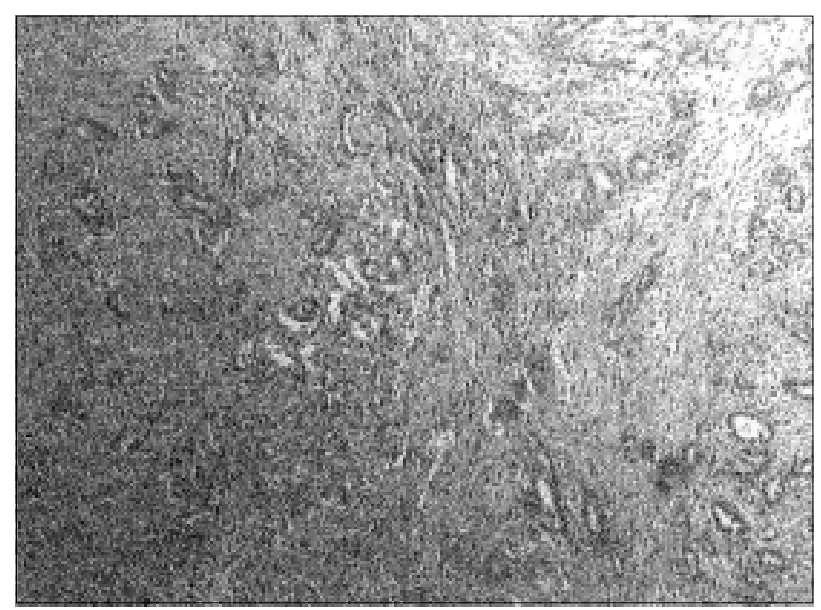

Figura 1 - Microfotografia de implante tumoral em sítio de trocáter umbilical (HE 100X).

\section{Caso 2}

Homem de 78 anos com história de vários episódios de cólica biliar nos últimos cinco anos. A ultra-sonografia

1. Professor Titular e Coordenador da Disciplina de Cirurgia do Aparelho Digestivo da Universidade Federal do Paraná e Chefe do Serviço de Cirurgia Geral do Hospital Nossa Senhora das Graças

2. Médico Residente do Hospital Nossa Senhora das Graças

Recebido em 6/10/99

Aceito para publicação em 14/3/2000

Trabalho realizado no Serviço de Cirurgia Geral do Hospital Nossa Senhora das Graças de Curitiba-PR. 
evidenciou colelitíase. $\mathrm{O}$ paciente foi submetido à colecistectomia laparoscópica, sem intercorrências. A vesícula biliar foi retirada pela incisão do trocarte umbilical, sem o uso de saco plástico. Após a operação, observou-se espessamento de toda parede do fundo da vesícula. O paciente teve boa evolução pós-operatória.

O exame anatomopatológico evidenciou adenocarcinoma comprometendo até a serosa. Pela idade do paciente, os familiares optaram pela não realização de tratamento adicional. Nove meses após a colecistectomia, o paciente apresentou tumor de cerca de $4 \mathrm{~cm}$ no sítio de trocarte de $5 \mathrm{~mm}$ utilizado para tracionar a vesícula biliar.

A biópsia do tumor revelou adenocarcinoma. A ultra-sonografia identificou dois nódulos hepáticos, sugestivos de metástases. Não havia outras alterações ultrasonográficas. O tratamento optado pelos familiares foi o expectante.

\section{DISCUSSÃO}

A neoplasia de vesícula biliar apresenta uma incidência na literatura entre $0,34 \%$ a $2,85 \%$ das colecistectomias realizadas por colecistolitíases na dependência da faixa etária dos pacientes submetidos ao procedimento ${ }^{3,4}$. Estima-se que a incidência média das neoplasias incidentais deve variar em torno de $0,3 \%$ a $0,4 \%$, devido ao aumento do número de procedimentos em pacientes mais jovens ${ }^{1}$. A neoplasia maligna da vesícula é em 60-90\% das vezes descoberta incidentalmente em uma cirurgia anteriormente prevista como benigna ${ }^{2}$.

A possibilidade de recorrência tumoral manifestada como doença disseminada e principalmente no sitio dos trocartes é objeto de controvérsia na literatura. $\mathrm{O}$ primeiro relato de implante tumoral em incisão da laparoscopia foi efetuado por Drouard et al..$^{5}$, seguido de uma série de relatos semelhantes por outros auto- res, enfatizando o papel da laparoscopia na disseminação precoce destas neoplasias ${ }^{2-5}$. O mecanismo de implante tumoral não está esclarecido e as seguintes teorias têm sido sugeridas: manipulação aumentada da vesícula biliar, perfuração da vesícula com extravasamento de bile com células neoplásicas, remoção da vesícula tumoral e de instrumentos através do sítio do trocarte e conseqüente implante de células tumorais e redução da defesa imunológica pelo $\mathrm{CO}_{2}$ insuflado no abdome ${ }^{1,2,5}$. No nosso primeiro caso, o mecanismo de implante tumoral foi possivelmente o contato direto da vesícula biliar e o consequiente implante de células tumorais no sítio do trocarte e, no segundo caso, o contato da pinça de tração da vesícula contendo células tumorais com o sítio do trocarte.

Entretanto, alguns autores relatam que o implante metastático em parede abdominal não aumenta após a cirurgia laparoscópica e depende principalmente da agressividade natural deste tumor ${ }^{1}$. Ricardo et al. ${ }^{1}$ do M.D. Anderson Hospital relataram que a incidência de implante no sítio dos trocartes após colecistectomia laparoscópica é similar ao implante na cicatriz de laparotomia após colecistectomia aberta.

O implante apresenta-se como uma massa subcutânea dolorosa, aparecendo de semanas a meses após a cirurgia. O sítio umbilical é o relatado com maior freqüência, principalmente devido ao maior contato com as células malignas durante a retirada da vesícula ${ }^{2,3}$. Outros sítios também podem contribuir para a disseminação de células neoplásicas durante a manipulação da vesícula devido à constante colocação e retirada dos instrumentos pelos trocartes ${ }^{2}$. Tem sido sugerido que a retirada da vesícula em sacos plásticos apropriados pode reduzir a incidência de disseminação de células tumorais $^{1}$. O implante tumoral pode ocorrer mesmo em pacientes com neoplasia sem invasão da serosa, como em um dos casos descritos por nós.

\begin{abstract}
The authors present two cases of unsuspected carcinoma of the gallbladder after laparoscopic cholecystectomy in which trocar site metastasis developed during their follow-up. In the first case, a 68 year-old woman with cholecystolithiasis underwent an uneventful laparoscopic cholecystectomy. Histologic examination revealed adenocarcinoma invading the mucosa and muscular layers of the gallbladder. The patient refused additional treatment. Seven months later, metastasis developed in the umbilical port site, which was excised. In the second case, laparoscopic cholecystectomy was performed for a symptomatic gallstone in a 78 year-old man. The gallbladder inspection showed thickenning of the infundibulum wall. Histological examination revealed adenocarcinoma invading serosa. No additional treatment was performed because of the patient's advanced age. A metastasis was identified in the $5 \mathrm{~mm}$ port site nine months after the operation. Two hepatic metastasis were also demonstrated by ultrasonography.
\end{abstract}

Key Words: Gallbladder carcinoma; Laparoscopic cholecystectomy; Neoplasm recurrence. 


\section{REFERÊNCIAS}

1. Ricardo AE, Feig BW, Ellis LM, et al. - Gallbladder cancer and trocar site recurrences. Am J Surg 1997, 174:619-23.

2. Jeon HM, Kim JS, Lee CD, et al. - Late development of umbilical metastasis after laparoscpic cholecystectomy for a gallbladder carcinoma. Oncol Rep 1999, $6: 2,283-7$.

3. Mori T, Souda S, Hashimoto J, et al. - Unsuspected gallbladder cancer diagnosed by laparoscopic cholecystectomy: a clinicopathological study. Surg Today 1997, 27:8,710-3.

4. Zgraggen K, Birrer S, Maurer CA, et al. - Incidence of port site recurrence after laparoscopic cholecystectomy for preoperatively unsuspected gallbladder carcinoma. Surgery 1998, 124:5,831-8.
5. Drouard F, Delamarre J, Capron J - Cutaneous seeding of gallbladder cancer after laparoscopic cholecystectomy. N Engl J Med 1991,325:1316.

\section{ENDEREÇO PARA CORRESPONDÊNCIA}

Dr. Júlio Cezar Urli Coelho

Rua Bento Viana, 1140/2202

80240-110 - Curitiba-PR

Fone/Fax:(041)322-3789 